\title{
Retrofitting for Lathe Machines
}

\author{
Vikrant D. Nichit ${ }^{1}$, Neha S. Dixit, Mugdha V. Bhadak ${ }^{3}$ \\ ${ }_{1}^{1}$ Mechanical Engineering Department \& K. K. Wagh I.E.E. R., Nashik \\ ${ }^{2}$ Mechanical Engineering Department \& K. K. Wagh I.E.E. R., Nashik \\ ${ }_{3}^{3}$ Mechanical Engineering Department \& K. K. Wagh I.E.E. R., Nashik
}

\begin{abstract}
Old machines often breakdown unpredictably increasing your expenses through maintenance costs and lost production. In the present era various modern technologies are been emerging in the field of manufacturing which are proven to be disruptive. For the established industries and their machine tools sometimes it is difficult to cope up with current scenario. Hence retrofitting is an emerging term where improvisation of the old setups of machines can be done. Retrofitting refers to the addition of new technology or features to older systems. Machine Tool Technologies recondition worn machine tools that have taken a beating in the course of production. The main objective is to study low cost automation technique for old machine as well as to study different parameters of retrofitting of old machine. In retrofitting attempt is made to equip the machines with digital intelligent system in order to get the more accurate dimensions and precise shape of high end products. So it is required to convert this conventional lathe into semiautomatic lathe by retrofitting. The paper emphasis on how a lathe can be converted to upgraded version by retrofitting. Also it includes the flow chart of retrofitting.
\end{abstract}

Key Words: Retrofitting, Reconditioning, CNC, Lathe Machines, Low Cost Automation

\section{INTRODUCTION}

Retrofitting is an addition of new technology or some features to older setup, this definition gives almost all information about the word retrofitting. In simple words, we can say retrofitting means up gradation of the older setup with improving their efficiency through the present technology. Machine tools are critical in manufacture of metal parts. As CNC machine tools are widely used across the entire world, they can be extremely expensive investments to make, even for large manufacturing businesses.

The machine tool reconditioning process rejuvenates the machine giving great performance levels. This reduces maintenance costs and losses incurred due to increased downtime. This is particularly important for high-volume operations. Machine Tool Reconditioning Options are that Major modifications such as changing critical geometries such as Replacement, Retrofitting, commissioning, Re-erection, Recalibration. In this we will focus on retrofitting for lathe machine. Benefit of retrofitting is low cost investment than purchasing a new machine. The anticipated benefit of retrofitting is low cost investment than purchasing a new machine. [3]

Retrofitting also leads to unanticipated benefits which includes high performance, reduce consumption of power, lower energy cost and increases operational efficiency.
Most industrial equipment is been installed to last at least few years but up to that time a lot of significant and new technology is been introduced. So it becomes difficult for industry to cope up with the current scenario.

Many manufactures pursue ways to get advantages of advanced or highly upgraded manufacturing technology without having to change current equipment that remains in fine working condition. Most of the small shop just can't pay for the planned replacement and so nearly 75-80\% of old machines are working for last 20 years and are still in use. So when you consider an upgrade and look forward for automation systems considering all the parameters you have three options:

a) Tear and change whole prevailing system,

b) Retrofitting old system with new machinery,

c) Keep the old system running as long as possible?

If we keep the old system running there can be two cases, which include fixing and maintaining broken machinery or running an old system which can be trial but not impossible. [4]

\section{LITERATURE SURVEY}

S.Sridevi, J.Dhanasekar, G.Manikandan explains her method of work regarding Retrofitting for CNC Vertical Milling Machine. They developed novel methodology for the retrofitting of milling and turning machines in this methodology industrial standard breakout board, motor driver, motors and sensors are used. So the service time of the machine can be increased with low cost. This system can be adaptable for various types of CAD/CAM software. [2]

Diego H. Arjoni, Emília Villani explains their work in paper named as Manufacture Equipment Retrofit to Allow Usage in the Industry 4.0. They conclude that the retrofit alternatives presented allowed older machines to be used in industry 4.0. It must be taken into account that some of these machines are more rudimentary than those normally employed, such as the CNC proLIGHT. In this way, the retrofit techniques described can be adopted to develop the interface of a wide range of industrial machines currently in use. From the developed implementations, it can be concluded that the retrofit strategies have a good cost benefit, allowing old equipment to be, used as elements of the advanced manufacture with little effort of programming and mechanical adaptation. [1]

\section{Case study on Retrofitting}

Low cost automation can also be related to implementation of an automation system. This is very easy and facilitates the maintenance, however, is very often considered 


\section{International Journal of Scientific Research in Engineering and Management (IJSREM)}

as critical point and important cost factor. A standardization of components of automation system is very distribution and innovation in new application. Basically the German manufacturing industry introduced low cost automation as a tool for saving the cost. Batch production will become very easy. Production time is less so minimum products are increased. [2]

The reliability of low cost automation is independent on grade of automation i.e. to cover all possible circumstances in its field of any application. Therefore retrofitting is a lowest cost solution to improve the overall performance of older machine. [3]

A retrofit allows a manufacturing unit to lower the cost at the cost of reconstruction, remanufacturing or retrofitting which is around $1 / 3 \mathrm{rd}$ or $2 / 3 \mathrm{rd}$ the cost of new machine. Retrofitting includes an upgrade which allows improving the mean time to repair, as the updated machine will make it possible to alert the operator of processes and down time failures. This alert helps to improve our response time to get the issues resolved to minimize the downtime.

Retrofitting helps to push down the energy back into the line on slowing down, i.e. it reduces the energy consumption.

This system with improved machine processes try to save power cost as much as 30-50\%. So the main aim of the retrofitting in lathe machine is to improve the existing conventional lathe machine to provide it features of $\mathrm{CNC}$ machine with very lower cost than the new CNC machine.

The retrofit alternatives presented allowed older machines to be used in industry 4.0. It must be taken into account that some of these machines are more rudimentary than those normally employed, such as the CNC proLIGHT. In this way, the retrofit techniques described can be adopted to develop the interface of a wide range of industrial machines currently in use. [1]

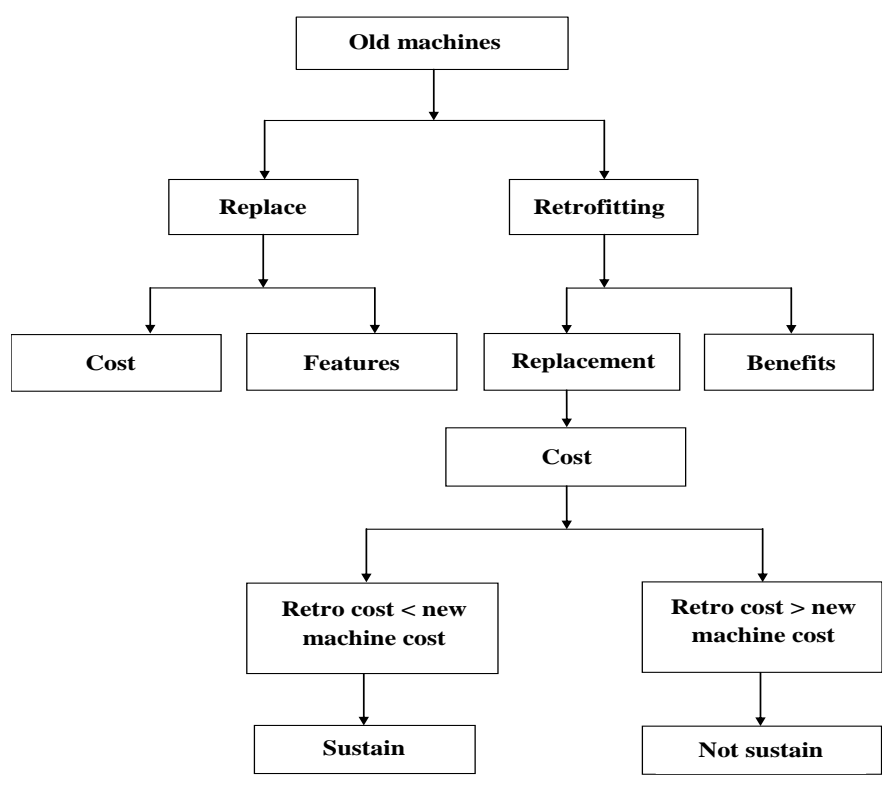

Fig -1: Retrofitting

As our study on retrofitting we have done in our workshop. We decided to retrofit the old machine by changing some of the parts. So we list out the parts which can be retrofitted and then decided which part of machine is essential to retrofit.
We had some machines which were rarely used due to the work done by other machines, so these were only occupying space .So the company decided to retrofit some parts of these machines and make it able to work efficiently. [3]

There were 3 lathe machine which were rarely used because all work was done on CNC and VMC machine; also they were also occupying more space. So a point came out what should be done. So the company started analyzing it and discussing to either replace it with new machine or to keep those machines and change some of the component according to their need. So there was a discussion done whether they could replace the machine with new $\mathrm{CNC}$ machine, but the cost factor will play an important role because a new machine will cost too much, but they will get more feature in new machine than the lathe machine.

But after discussion we came up with a thought if we bring some of the feature of $\mathrm{CNC}$ in the lathe machine by replacing some parts of lathe machine and making it automated so it will be a low cost investment rather than purchasing new machine and also they can use the retrofitted machine for large scale production. So discussion was done to what to retrofit, which parts can be used as it is, which parts have to be replaced, so in this way what changes should be done with considering the cost factor were finalized, because if they retrofit the machine and its cost is close to or more than the new machine then retrofitting is not sustainable. So we list out the parts which can be retrofitted and then decided which part of machine is essential to retrofit.

Table -1: Numbers of parts which can be retrofitted

\begin{tabular}{|l|l|l|c|l|}
\hline Srno & Part of the machine & Retrofit of that part & $\begin{array}{l}\text { Cost of } \\
\text { retrofit }\end{array}$ & $\begin{array}{l}\text { Selected } \\
\text { or not }\end{array}$ \\
\hline 1 & Lead screw & Ball screw & 15000 & Selected \\
\hline 2 & Manually operated 4 jaw chuck & Automated 4 jaw chuck & 10000 & Selected \\
\hline 3 & Gear box & Servo motor. & 30000 & Selected \\
\hline 4 & Saddle & Stepper motor. & 8697 & Selected \\
\hline 5 & Tool post & Permanent magnet stepper & 2499 & Rejected \\
& & motor. & & \\
\hline 6 & Tailstock & Stepper motor & 2000 & Rejected \\
\hline
\end{tabular}

So there were 6 parts which can be retrofitted that is lead screw, four jaw chuck, gear box, saddle, tool post, Tailstock. But we decided to retrofit only 4 parts which are lead screw, four jaw chuck, saddle, and gear box. We rejected to retrofit tool post and tailstock because according to their point of view there was no such need through discussion with other. Basically it can be manually operated so we try to reduce the cost by not making it automated. So the first retrofit was replacing the lead screw with the ball screw for achieving fast sliding motion. Then we replace the four jaw chuck with automated four jaw chuck so that it reduces the time for removing and fixing the job. The main retrofit was replacing the gear box with servo motor. Due to gear box we use to get only 4-5 variation of speed but after replacing it with the servo motor we can get different number of speeds as it controlled by dimmer stat. So we have used $3 \mathrm{Hp}$ servomotor and maximum speed is obtained as $5000 \mathrm{rpm}$. Then the next retrofit was saddle so it was made automated with the help of using stepper motor and ball screw arrangement. Due to which we get automatic cross feed in $\mathrm{X}$ and $\mathrm{Z}$ direction. We 


\section{International Journal of Scientific Research in Engineering and Management (IJSREM)}

have also joined a computer to the lathe machine for giving the automatic cross feed according to the requirement. For this they are using Mach3 software. The table given below illustrates that which parts of the machine are retrofitted.

Table -2: Numbers of parts which can be retrofitted

\begin{tabular}{|l|l|l|}
\hline Sr.no & Part of the machine & Retrofit of that part \\
\hline 1 & Lead screw & Ball screw \\
\hline 2 & Manually operated 4 jaw chuck & Automated 4 jaw chuck \\
\hline 3 & Gear box & Servo motor. \\
\hline 4 & Saddle & Stepper motor. \\
\hline
\end{tabular}

By developing automation in conventional lathe machine by retrofitting, the machine works as a CNC machine. By retrofitting cost of machine is minimizing approximate 3 times below the original $\mathrm{CNC}$ machine. The jobs which are not manufactured on conventional lathe machine are manufactured in retrofitted lathe machine. Therefore retrofitting is typically low cost solution to improve the overall performance of older setup.

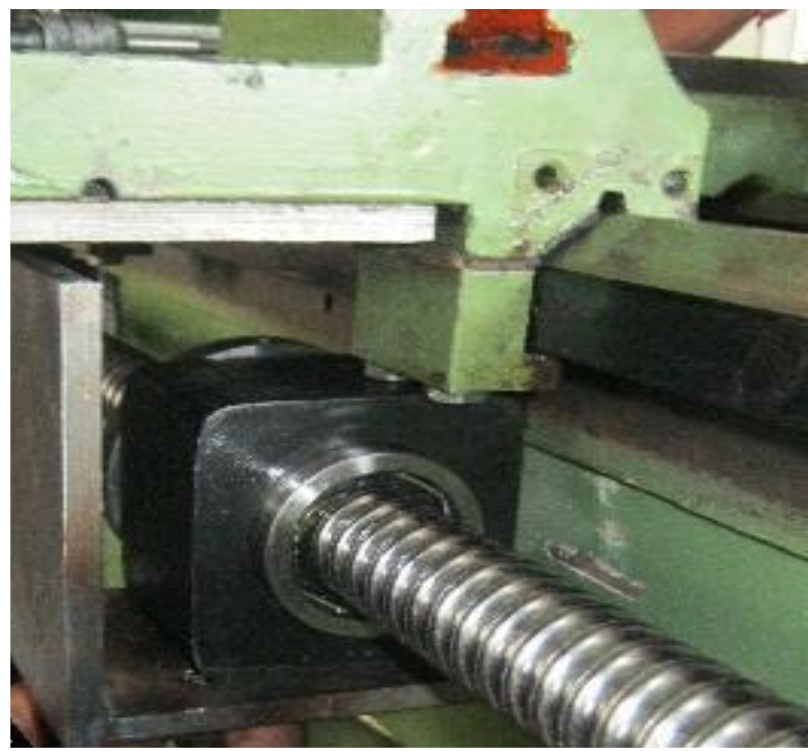

Fig -2: Z-axis ball screw attached on main slide

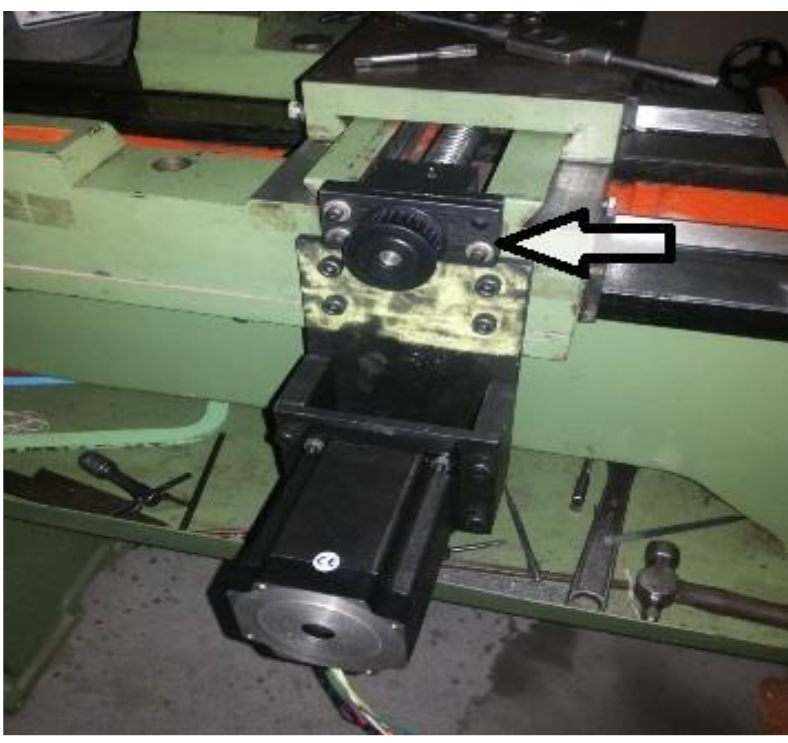

Fig -3: X-axis mounting \& stepper motor

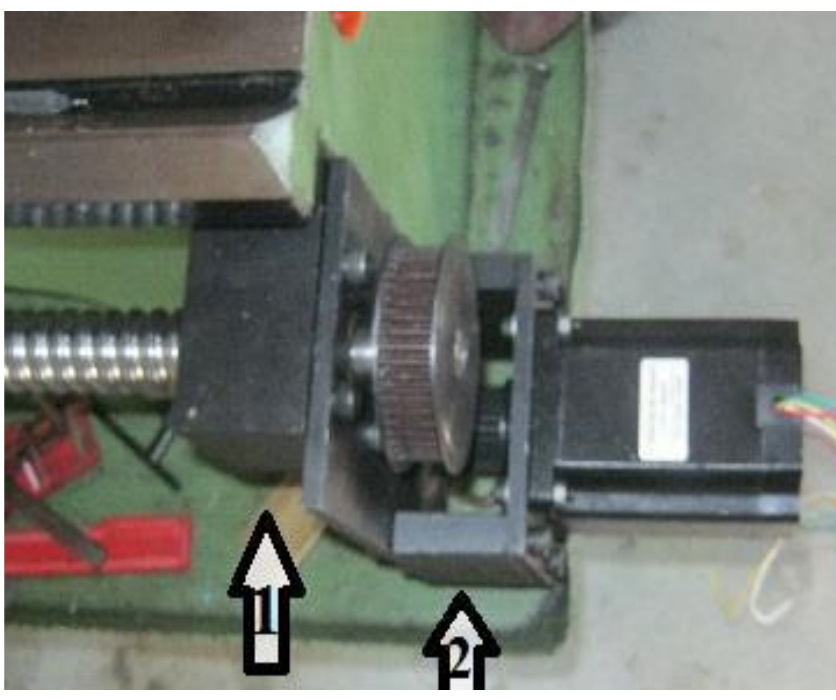

Fig -4: Z-axis Mounting bracket \& Stepper motor

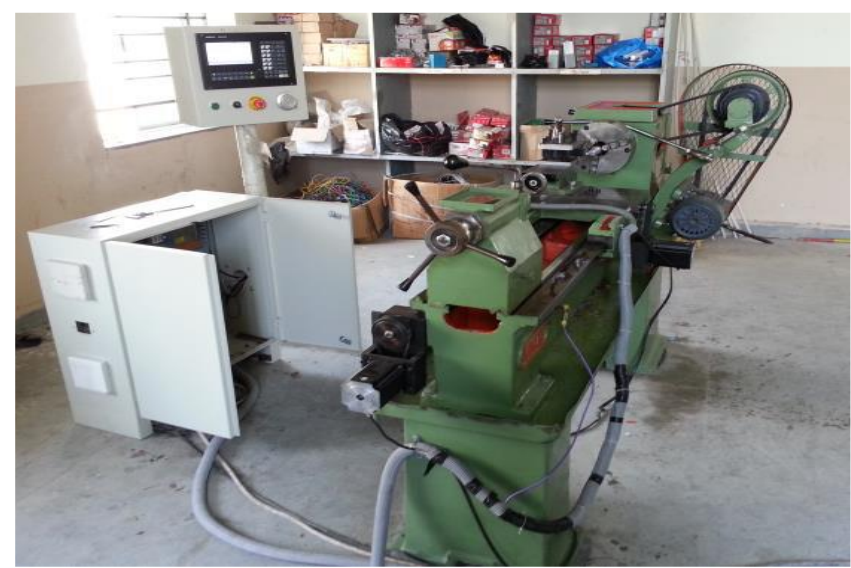

Fig -5: Developed retrofitted lathe machine 


\section{CONCLUSIONS}

Conclusion for this paper is as conclusion of case study. As technology is emerging in day to day life retrofitting is the best method to upgrade your system with current technology. Conventional lathe machine is converted into retrofit lathe machine by replacing or removing the component therefore the setup cost is high. But it is very useful for mass production. The accuracy of the job manufactured by retrofitted lathe machine is also high as well as efficiency of machine also increases so repeatability and dimensional stability of manufactured part is achieved.

The jobs which are not manufactured on conventional lathe machine are manufactured in retrofitted lathe machine. The retrofit alternatives presented allowed older machines to be used in industry 4.0. Therefore retrofitting is typically low cost solution to improve the overall performance of older setup.

\section{REFERENCES}

[1] Diego H. Arjoni, Emília Villani, Manufacture Equipment Retrofit to Allow Usage in the Industry 4.0, 20172017 2nd International Conference on Cybernetics, Robotics and Control, 2017

[2] S.Sridevi, J.Dhanasekar, G.Manikandan, A Methodology of Retrofitting For CNC Vertical Milling Machine, International Conference on Robotics, Automation, Control and Embedded Systems, 18-20 February 2015, Hindustan University, Chennai, India

[3] mtt.uk.com/machine-tool-reconditioning/

[4]https://www.industrialautomationindia.in/articleitm/3 58/Low-Cost-Automation:-Retrofitting-Old-Machines/articl 